\title{
Diagnostic Downscaling of Large-Scale Wind Fields to Compute Local-Scale Trajectories
}

\author{
ANDREAS STOHL \\ Institute of Meteorology and Physics, University for Agricultural Sciences, Vienna, Austria \\ KATHRIN BAUMANN \\ Central Institute for Meteorology and Geodynamics, Vienna, Austria \\ GERHARD WOTAWA \\ Institute of Meteorology and Physics, University for Agricultural Sciences, Vienna, Austria \\ MATTHIAS LANGER \\ Central Institute for Meteorology and Geodynamics, Vienna, Austria \\ BRUNO NEININGER \\ MetAir AG, Illnau, Switzerland \\ MARTIN PIRINGER \\ Central Institute for Meteorology and Geodynamics, Vienna, Austria \\ HERBERT FORMAYER \\ Institute of Meteorology and Physics, University for Agricultural Sciences, Vienna, Austria
}

(Manuscript received 12 August 1996, in final form 12 November 1996)

\section{ABSTRACT}

\begin{abstract}
This paper describes a simple method, based on routine meteorological data, to produce high-resolution wind analyses throughout the planetary boundary layer (PBL). It is a new way to interpolate wind measurements. According to this method, high-frequency information from surface wind measurements is extrapolated to greater heights by assuming that the vertical shear of the horizontal wind, that is, the differential vertical wind profile, is horizontally more homogeneous than the wind profile itself. Under this assumption, it is sufficient to combine high-resolution surface wind measurements with low-resolution vertical profiles of differential winds-for which high-resolution measurements usually do not exist - to yield high-resolution wind analyses throughout the PBL. The method can thus be viewed as a diagnostic downscaling of large-scale wind fields. Downscaling works best during daytime within a homogeneous air mass and in flat terrain. A validation against sodar wind measurements demonstrates that downscaling actually improves large-scale wind fields. A comparison of trajectories calculated from large-scale wind fields, from downscaled wind fields, and from wind fields produced by a conventional diagnostic wind field model, with daytime constant level balloon flights, again shows that the downscaled wind fields are most accurate.
\end{abstract}

\section{Introduction}

In air pollution studies, accurate three-dimensional wind fields are needed to drive Eulerian chemical mod-

Corresponding author address: Dr. Andreas Stohl, Institute of Meteorology and Geophysics, University of Vienna, Hohe Warte 38, A-1190 Vienna, Austria.

E-mail: andreas.stohl@zamg.ac.at els (e.g., Jakobs et al. 1995) or to compute trajectories to investigate the transport of pollutants. In this paper, we focus on the calculation of local-scale wind fields for which two different methods are frequently applied. On the one hand, diagnostic models analyze measured wind data and interpolate them to a regular grid (e.g., Sherman 1978; Goodin et al. 1980; Ross et al. 1988; Mathur et al. 1990; Scire et al. 1990; Ludwig et al. 1991). On the other hand, prognostic mesoscale models have become increasingly popular in recent years (e.g., 
Schlünzen 1994; Kunz and Moussiopoulos 1995; Peters et al. 1995). Both approaches, however, face some difficulties.

Prognostic meteorological models require large computer resources and a lot of high-resolution input data that are often not available with sufficient accuracy for applications on the local scale (McQueen et al. 1995). They must be supplied with initial and boundary conditions that are not easy to specify. If they are to serve as analytical tools, advanced data assimilation techniques, such as optimal nudging (Zou et al. 1992) or four-dimensional variational data assimilation (Talagrand and Courtier 1987) that require substantial expertise and large computer resources, are essential.

Diagnostic wind field models require less computing time and less input data than prognostic models. A common approach to construct diagnostic wind fields consists of four steps. First, surface winds are interpolated to a regular grid. For that, several interpolation techniques have been proposed, such as inverse distancesquared weighting (Goodin et al. 1979), inverse elevation difference weighting (Palomino and Martin 1995), or more advanced techniques like statistical (optimum) interpolation (Daley 1991). Second, upper-level wind data are interpolated to the three-dimensional grid. Third, topographic effects, slope winds and blocking are parameterized (Scire et al. 1990). Fourth, the threedimensional wind fields are adjusted to ensure the conservation of mass (Moussiopoulos and Flassak 1986; Brocchini et al. 1995).

Although parameterizations done in the third step may partly account for small-scale dynamic effects, the effective resolution of diagnostic models is essentially limited by the resolution of the monitoring network. Surface wind measurements are often available with relatively high spatial and temporal resolution, but upperlevel measurements, usually taken from radiosondes, have a much lower resolution, typically 6-12 $\mathrm{h}$ in time and $100-400 \mathrm{~km}$ horizontally. Therefore, interpolation of radiosonde winds causes large errors. Kahl and Samson (1986) found average spatial and temporal interpolation errors of 3-4 $\mathrm{m} \mathrm{s}^{-1}$ at a height of $1000 \mathrm{~m}$, causing substantial degradation of the accuracy of computed trajectories (Kahl and Samson 1988a). Even larger interpolation errors occur under highly convective conditions, when mesoscale structures are not sufficiently resolved by the radiosonde network (Kahl and Samson 1988b).

Thus, although diagnostic models may produce highly resolved surface-level wind analyses, their upper-level analyses are poorly resolved and thus inaccurate. This is not very satisfying and severely limits the applicability of these models to air pollution problems because air pollutants are transported throughout the whole planetary boundary layer (PBL) and in residual layers aloft (Stull 1988; Stohl and Wotawa 1995). Critical comments on the suitability of diagnostic models to compute wind fields at upper levels and in complex terrain can also be found in Graber and Portmann (1993) and Richner and Griesser (1993). Nevertheless, most diagnostic models are evaluated against surface measurements only (e.g., Bridger et al. 1994; Seibel and Maßmeyer 1995). Deficiencies or inadequate resolution at upper levels are rarely detected or discussed.

In this study we propose a simple alternative method to produce highly resolved wind analyses. Using highresolution surface measurements, we downscale largescale wind fields provided by a numerical weather prediction model. Special attention is paid to a correct treatment of vertical wind profiles in order to produce highly resolved wind analyses throughout the PBL, not only close to the ground.

\section{Evaluation of data sources for analyzing wind fields}

There are limited types of routine wind data available that are suitable for analyzing local-scale wind fields. Most important are surface and radiosonde wind measurements that are required by nearly all diagnostic wind field models. In addition, wind analyses produced by numerical weather prediction models are often available, but up to now they have not been used for analyzing local-scale wind fields. Although new sounding techniques have been developed in recent years (for instance, sodars and wind profilers), these data are seldom available in routine networks.

Surface wind measurements are the source of data with the highest resolution in both space and time, and thus it is desirable to use these data for analyzing wind fields on the local scale. However, surface measurements are strongly influenced by the topography in the immediate vicinity of the station. Therefore, their representativity for the scale considered must be investigated before they are used.

We selected a region in eastern Austria that covers both relatively simple and complex topography and examined the representativity of the surface wind measurements available in that region (Fig. 1). Hourly data covering the period from April to September 1994 were used to investigate the spatial correlation of wind measurements employing a method described by Hanna and Chang (1992). Stations were combined into pairs and the correlations between their wind data were examined. We used the concept of vector correlation as introduced by Crosby et al. (1993) and Breaker et al. (1994). For two-dimensional vectors like the horizontal wind vector, squared vector correlation coefficients $r_{v}^{2}$ vary between 0 (no correlation) and 2 (perfect linear correlation).

Overall, correlations declined with increasing distance between the stations (Fig. 2). Here $r_{v}^{2}>1$ were only found for distances below $100 \mathrm{~km}$. There was, however, considerable scatter in the correlations and station pairs with uncorrelated winds $\left(r_{v}^{2}<0.2\right)$ existed even at the shortest distances. We found that practically all station pairs with high $r_{v}^{2}$ were located in the eastern 


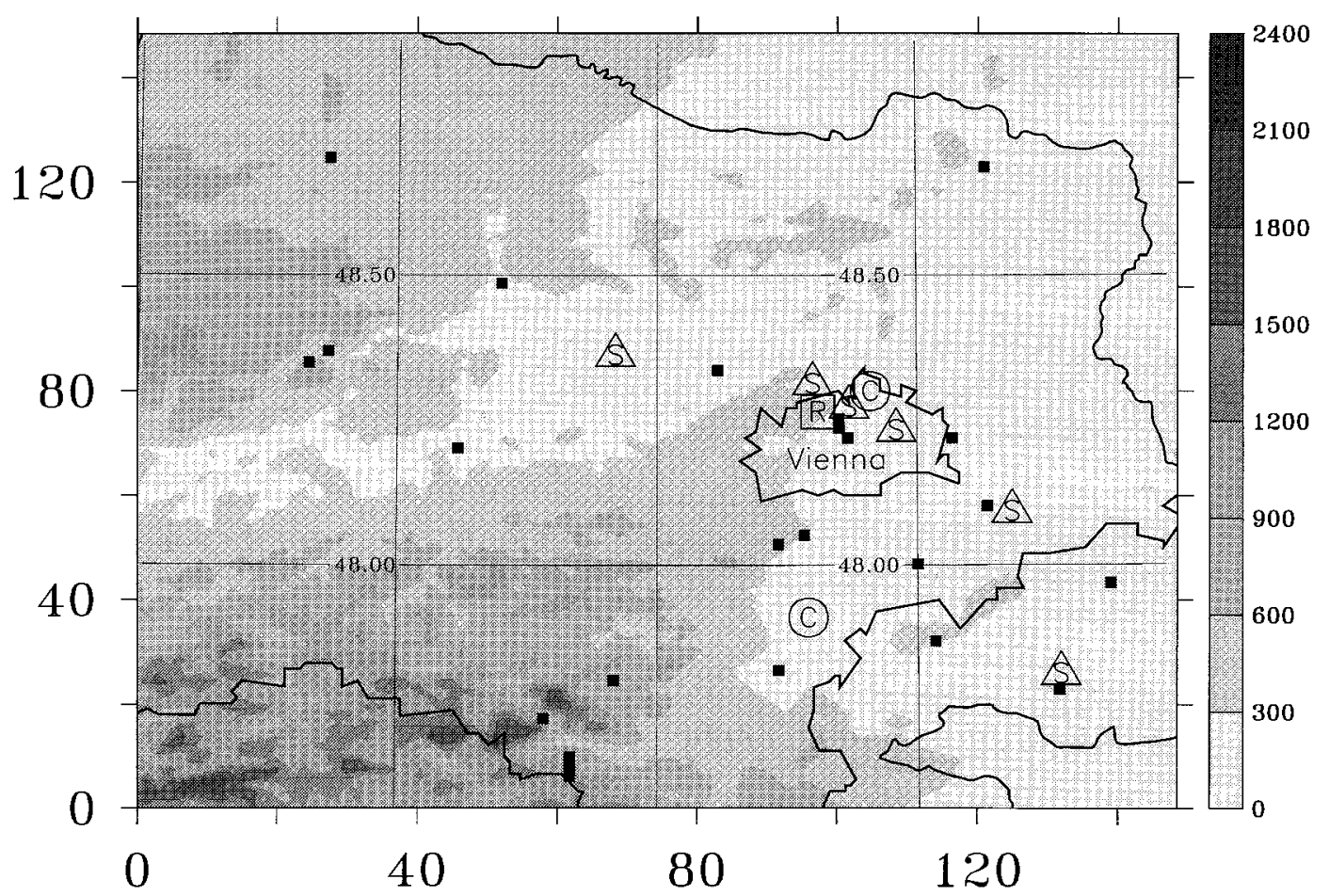

FIG. 1. Topography of the investigation area with altitudes above sea level $(\mathrm{m})$ indicated by the shading. The lines are the borders of the Austrian federal states Lower Austria, Vienna, and Burgenland. Distances are given in kilometers; surface wind station locations $(\square)$, radiosonde location $(\square)$, sodar sites $(\triangle)$, constant-level balloon release points $(\bigcirc)$.

part of the investigation area, where the topography is less complex than in the western part. Station pairs located in the mountainous western part of the investigation area were nearly uncorrelated.

During nighttime, a stable PBL with a ground-based

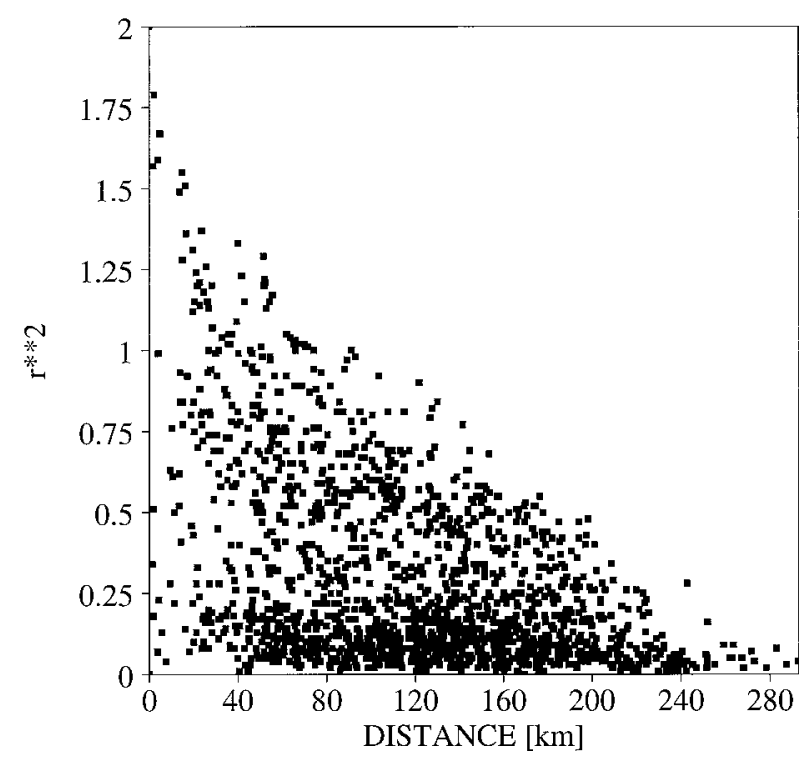

FIG. 2. Dependence of the squared wind vector correlation coefficients between station pairs on the separation of the pairs. inversion develops. Under these conditions, the orography exerts a great influence on the low-level wind field, whereas under convective conditions during daytime, its influence is much less pronounced. Therefore, winds measured at two stations should correlate better during the day than during the night. This hypothesis was confirmed by finding higher $r_{v}^{2}$ during daytime than during nighttime. Taking into account only stations in the east of the investigation area and only data during daytime improved correlations further (Fig. 3).

In summary, the representativity of surface wind measurements is highest during daytime and in topographically simple terrain. Under these conditions, relatively high vector correlations are found. Thus, surface measurements should be suited to analyze daytime wind fields above not too complex terrain. The representativity of surface wind measurements is very poor during nighttime and in complex terrain. Under these conditions, analyzed surface wind fields are highly uncertain.

Wind information at greater heights is usually available from numerical weather prediction models or from radiosondes. It must be decided on which database wind field analyses are to be based. We use analyzed fields of the T213 L31 model of the European Centre for Medium-Range Weather Forecasts (ECMWF 1989) with 213 resolvable waves around the globe and 31 vertical levels. Of these, nine levels are below $2800 \mathrm{~m}$ above ground, a vertical resolution comparable to that of rou- 


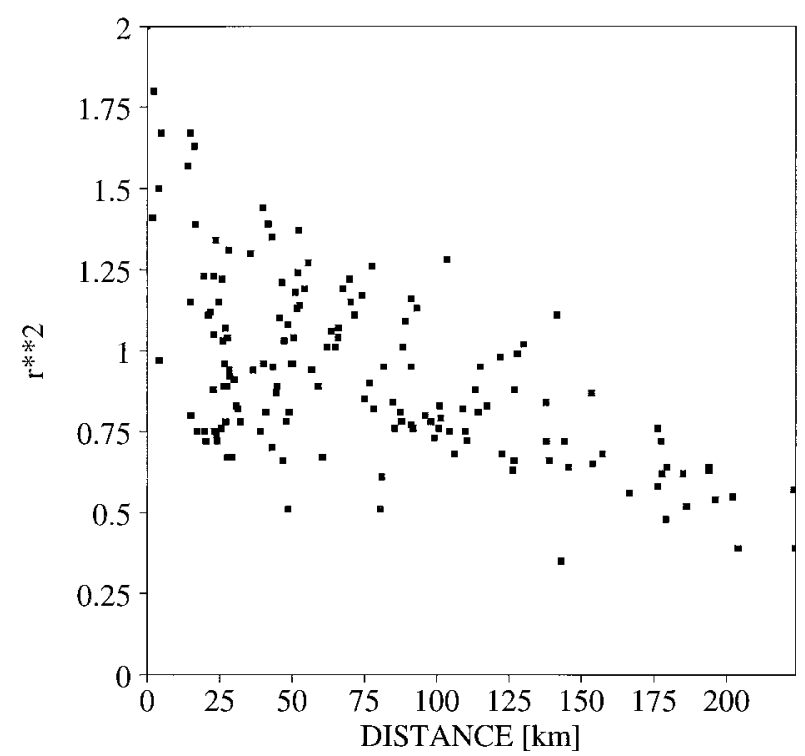

FIG. 3. Same as Fig. 2 but for the stations in the eastern part of the investigation area and during daytime only.

tinely available radiosonde data. Throughout this study, the original ECMWF hybrid eta coordinate system is used, where the lowest model levels follow the topography and the highest levels coincide with pressure surfaces. The data were extracted on a grid with $0.5^{\circ}$ (approximately 40 and $55 \mathrm{~km}$ longitudinal and latitudinal) resolution, less than the average separation of radiosonde sites (approximately 100-400 km in Europe). Initialized analyses were available from the archives at ECMWF every $6 \mathrm{~h}$ (0000, 0600, 1200, and 1800 UTC). Three-hour short-range forecasts were used at times when analyses were not available (0300, 0900, 1500, and 2100 UTC). Since both the spatial and the temporal resolutions of the ECMWF fields are higher than the resolution of the radiosonde network, it is preferable to use ECMWF model winds instead of radiosonde data for analyzing wind fields. Before ECMWF data were used, however, we investigated to see if their accuracy is comparable to that of the radiosonde data.

We compared wind measurements at the radiosonde station Vienna (Fig. 1) at the pressure levels 925, 850, and $700 \mathrm{hPa}$ at 0000 and $1200 \mathrm{UTC}$ with wind data at the closest ECMWF model grid point for the period April-September 1994. Model winds were vertically interpolated from the levels of the ECMWF model (ECMWF 1989) to the pressure levels using linear interpolation. Table 1 shows the results. Root-meansquare wind speed deviations were around $1.5 \mathrm{~m} \mathrm{~s}^{-1}$, root-mean-square wind direction deviations were between $14^{\circ}$ and $20^{\circ}$, and squared vector correlations were above 1.75 at all three levels, indicating excellent agreement between measurements and ECMWF analyses. Since radiosonde observations were used in the analysis procedure, this result is not surprising, but it confirms that ECMWF model winds near sounding locations can
TABLE 1. Root-mean-square deviations of wind speed rms (ff) and wind direction $\mathrm{rms}(\varphi)$ and squared vector correlation coefficients $r_{v}^{2}$ between ECMWF model analysis and radiosonde observations in Vienna at 925, 850, and $700 \mathrm{hPa}$, respectively.

\begin{tabular}{cccc}
\hline \hline $\begin{array}{c}\text { Level } \\
(\mathrm{hPa})\end{array}$ & $\begin{array}{c}\text { rms (ff) } \\
\left(\mathrm{m} \mathrm{s}^{-1}\right)\end{array}$ & $\begin{array}{c}\mathrm{rms}(\varphi) \\
\left({ }^{\circ}\right)\end{array}$ & $r_{v}^{2}$ \\
\hline 925 & 1.47 & 19.6 & 1.76 \\
850 & 1.47 & 15.2 & 1.78 \\
700 & 1.60 & 14.1 & 1.84 \\
\hline
\end{tabular}

substitute for radiosondes in analyzing wind fields. In regions and at times without available radiosondes, analyses of numerical weather prediction models, although less accurate than in regions with dense observation data, may be the only reliable source of information on the upper-level winds.

\section{Downscaling method}

Diagnostic wind field models usually interpolate winds at higher levels directly from radiosonde data, whereas surface winds, available at higher resolution, affect only the lowest model level(s). This effectively reduces the time and space resolution of upper-level wind analyses to the low frequency of radiosondes. We propose a method that extrapolates high-frequency surface information to greater heights using differential vertical profiles of the horizontal wind from low-resolution wind analyses of the ECMWF model.

The basic idea of the downscaling procedure is that vertical wind shears (i.e., vertical profiles of differential horizontal wind) have a larger horizontal representativity than wind profiles themselves or surface winds. The differential wind is defined as the wind at a given height with the wind at the surface level $(10 \mathrm{~m})$ subtracted. Under this assumption, differential winds can be interpolated over greater distances than winds themselves with no more loss of information. On the other hand, surface winds can only be interpolated over relatively short distances, but this is not so limiting since they are available with higher resolution. The downscaling is described by

$$
\begin{aligned}
\mathrm{ff}_{l}^{d} & =\mathrm{ff}_{l}^{o}+\left(\mathrm{ff}_{l}^{m}-\mathrm{ff}_{s}^{m}\right), \\
\varphi_{l}^{d} & =\varphi_{l}^{o}+\left(\varphi_{l}^{m}-\varphi_{s}^{m}\right),
\end{aligned}
$$

where $\mathrm{ff}$ is wind speed and $\varphi$ is wind direction, index $l$ denotes the $l$ th model level, $s$ is the surface, $d$ is downscaled, $o$ is measurements, and $m$ is the ECMWF model. Terms $\mathrm{ff}_{l}^{o}$ and $\varphi_{l}^{o}$ denote the measured surface wind speed and direction (the index $l$ here only indicates that surface winds are smoothed for use at higher levels). The significance of (1) is that measured surface winds are extrapolated into the vertical by adding differential vertical wind profiles taken from the ECMWF model. Equation (1) is applied only when $\mathrm{ff}_{l}^{m}>\mathrm{ff}_{s}^{m}$. Otherwise, unmodified ECMWF model winds are used.

For the practical application of the method, we first 
interpolate ECMWF model data to a resolution of $0.05^{\circ}$ (approximately $5 \mathrm{~km}$ ) and $1 \mathrm{~h}$, respectively, using bilinear interpolation in space and linear interpolation in time. Then we interpolate hourly surface wind measurements to the same mesh, using inverse distancesquared weighting (Goodin et al. 1979). Wind fields are smoother at higher levels than at lower levels because small-scale inhomogeneities in surface roughness, topography, etc., exert less influence. If the same surface winds would be used for downscaling at all levels, small-scale inhomogeneities experienced by the surface winds would be extrapolated to all levels. To avoid such unrealistic small-scale structures at higher levels, a separate interpolation of surface winds is done for each ECMWF model level, assuming a radius of influence for each station that increases with height. Near the surface, wind fields usually are so complex that the radius is taken as small as possible. The radius of influence $r_{i}(l)$ is computed according to the empirical formula $r_{i}(\mathrm{~km})=10 \mathrm{~km} \times l^{0.8}$, where $l$ is the number of the model level, counting from the lowermost to the uppermost level. If less than three stations are within the radius of influence, additional stations outside are used for the interpolation. Interpolated winds are not very sensitive to moderate modifications to the formulation of $r_{i}$.

Assuming that surface wind measurements provide information only on the wind field in the PBL, their influence is limited to this layer. Above the PBL, downscaling is therefore not applied and unchanged ECMWF winds are used. To avoid a discontinuity in the wind data at the PBL height $h$, a linear interpolation between downscaled winds and unchanged ECMWF winds is done in the entrainment zone (Stull 1988) between $0.8 \mathrm{~h}$ and $1.2 h$. The PBL height is taken as the maximum of the convective mixing height and the mechanical PBL height. Convective mixing heights are computed by scanning the potential temperature profile for the level where the potential temperature equals the surface value plus an excess temperature of thermals (Beljaars and Betts 1992). Mechanical PBL heights are diagnosed using an equation recommended by Koracin and Berkowicz (1988).

We do not reduce divergence to make the wind fields mass consistent because we use them only for computing trajectories. For this application, mass consistency is not needed. Our wind fields also do not contain vertical winds. They could be calculated by balancing the two-dimensional divergence contained in the fields with vertical motions. It is not clear, however, whether the downscaled wind fields are sufficiently accurate to allow this adjustment. Spurious vertical winds would be a likely result.

There are limitations to the application of the downscaling method. It cannot be expected that the basic assumption of horizontally homogeneous differential vertical wind profiles is generally fulfilled. For instance, areas ahead and behind a cold front may have different differential wind profiles. Thus, the assumption is best fulfilled within a homogeneous air mass. The representativity of surface winds is much reduced in complex terrain and under stable conditions because of the strong influence the topography exerts on the surface winds in this situation, a problem all diagnostic models face. Therefore, the method works best within a homogeneous air mass during daytime and in flat terrain, conditions fulfilled during photochemical smog episodes in eastern Austria. Thus, we use downscaled wind fields to calculate trajectories for our Lagrangian photochemical model.

\section{Validation of the downscaling method}

To study the applicability of the downscaling method and to validate downscaled wind fields against unmodified ECMWF wind fields, comparisons to independent measurements are done. First, ECMWF and downscaled upper-level winds are compared to winds measured with sodars. Second, trajectories computed from ECMWF and from downscaled wind fields are compared to trajectories derived from constant-level balloon (CLB) flights. The sodar measurements and constant-level balloon flights were conducted in flat terrain, conditions that are favorable for downscaling. We compare the performance of the downscaling method to that of a conventional diagnostic model.

\section{a. Comparison of model winds with sodar winds}

Sodar measurements are very suitable for validating the downscaling method because they provide independent wind information up to a few hundred meters above ground. During a few months of the year 1994, four Remtech PA2 sodars were operated by the Central Institute of Meteorology and Geodynamics (Piringer et al. 1995) and a Sensitron sodar was operated by the Austrian Federal Environmental Agency. The Sensitron sodar was again in operation in the year 1995. Table 2 gives the positions and operation periods of these sodars. Their locations are shown in Fig. 1.

The sodar measurements were compared with the interpolated but otherwise unchanged ECMWF winds and with the downscaled ECMWF winds at the closest grid point of the fine mesh. In the vertical, the model winds were interpolated to the sodar measurement levels.

We base our discussion on the squared vector correlation coefficients $r_{v}^{2}$ between modeled and measured winds and on the average errors in wind direction and wind speed with respect to the measured winds. Student's t-test (Press et al. 1992) was used to check whether the average errors for the downscaled and the ECMWF winds were significantly different, that is, whether the downscaling significantly improved ECMWF winds.

First, the whole dataset was used. At the lowest 510 sodar levels, the downscaled winds were better cor- 
TABLE 2. Locations, coordinates, types, heights above ground of the vertical levels, and operation periods of the sodars.

\begin{tabular}{lccccccc}
\hline \hline \multicolumn{1}{c}{ Location } & $\begin{array}{c}\text { Latitude } \\
\left({ }^{\circ} \mathrm{N}\right)\end{array}$ & $\begin{array}{c}\text { Longitude } \\
\left({ }^{\circ} \mathrm{E}\right)\end{array}$ & Type & $\begin{array}{c}\text { Lowest } \\
(\mathrm{m})\end{array}$ & $\begin{array}{c}\text { Highest } \\
(\mathrm{m})\end{array}$ & $\begin{array}{c}\text { Interval } \\
(\mathrm{m})\end{array}$ & Operation period \\
\hline Dürnrohr & 48.32 & 15.92 & PA2 & 60 & 820 & 40 & 30 June 1994-29 August 1994 \\
Hermannskogel & 48.27 & 16.30 & PA2 & 90 & 850 & 40 & 31 May 1994-29 August 1994 \\
Illmitz & 47.77 & 16.77 & Sensitron & 50 & 250 & 50 & 1 April 1994-25 September 1994 \\
Steinspornbrücke & 48.19 & 16.46 & PA2 & 70 & 830 & 40 & 30 May 1994-29 August 1994 \\
Stixneusiedl & 48.05 & 16.68 & Sensitron & 50 & 300 & 50 & 18 May 1995-13 September 1995 \\
TGM & 48.23 & 16.37 & PA2 & 120 & 880 & 40 & 12 July 1994-5 August 1994 \\
\hline
\end{tabular}

related with the measurements than the original ECMWF model winds at all stations (Table 3). At the lowest level, average wind direction errors were significantly reduced by the downscaling at four stations (Table 4), whereas at one station, the downscaling slightly increased, though not significantly at the $95 \%$ confidence level, wind direction errors. At the fifteenth level and above, no significant improvement of the wind directions was achieved by the downscaling. Mean wind speed errors were reduced at all sites except for Stixneusiedl, where errors were slightly increased (Table 5). For all other stations, wind speed errors were decreased up to the fifteenth level. At the twentieth level, differences were not significant.

As the representativity of the surface wind measurements is better during the day than during the night (see Fig. 3), the investigation was repeated for daytime (0700-1700 UTC) data only. While the daytime correlations between ECMWF model winds and sodar measurements were similar to those resulting from the complete dataset, correlations for the downscaled winds were much improved (Table 6). At the lowest sodar levels, $r_{v}^{2}$ ranged up to 1.7 (at Steinspornbrücke) for the downscaled wind fields, while $r_{v}^{2}$ for the ECMWF model reached only 1.4. For all sites except TGM, wind directions were (mostly highly significant) improved at all levels but the twentieth (Table 7), where few data were available (compare Table 6). Wind speeds were improved at all sites up to the tenth level (Table 8). Above, there was again no clear improvement.

From the data presented, it seems that the downscaling works best for the lowest few hundred meters of the boundary layer and during daytime. During nighttime (not shown), improvements are smaller. At levels above approximately $500 \mathrm{~m}$ AGL there is no improvement, but few sodar data are available above the tenth level (420-500 m AGL). Sodar measurement errors increase with height (Piringer 1994), reducing the significance of the comparisons at higher levels. Vector correlations for both ECMWF and downscaled winds decrease with height, also a possible indication that the measurements are less reliable at these heights. The sodar data sample at higher levels is also biased toward stable conditions because there the sodars gather fewer valid data during the afternoon hours on convective days (Piringer 1996). As the downscaling performs best under just these conditions, correspondence of the downscaled winds with measurements is impaired by this fact. Therefore, no final conclusion can be drawn, whether the downscaling improves wind fields at higher levels or not.

\section{b. Comparison of computed trajectories with balloon trajectories}

Balloons drift in the current and thus are quasiLagrangian tracers of horizontal air motions (Reisinger and Mueller 1983; Stocker et al. 1990; Knudsen and Carver 1994). The comparison of computed trajectories with trajectories derived from balloon flights allows a validation of the wind fields used for the trajectory computations. We calculated trajectories directly from ECMWF wind fields (hereafter referred to as ECMWF trajectories), from downscaled ECMWF wind fields (hereafter referred to as downscaled trajectories), and from wind fields of the diagnostic model TAMOS (hereafter referred to as TAMOS trajectories).

TAMOS, an improved version of the CALMET (cal-

TABLE 3. Number of cases $(N)$ and squared vector correlation coefficients $r_{v}^{2}$ between ECMWF winds (EC) and downscaled winds (DS) and winds measured by sodar at the first, fifth, tenth, fifteenth, and twentieth level, respectively, for the whole dataset. The heights of the levels are 60, 220, 420, 620, and $820 \mathrm{~m}$ above ground for Dürnrohr; 90, 250, 450, 650, and $850 \mathrm{~m}$ for Hermannskogel; 50 and $250 \mathrm{~m}$ for Illmitz and Stixneusiedl; 70, 230, 430, and $630 \mathrm{~m}$ for Steinspornbrücke; and 120, 280, 480, and $680 \mathrm{~m}$ for TGM.

\begin{tabular}{|c|c|c|c|c|c|c|c|c|c|c|c|c|c|c|c|}
\hline \multirow[b]{2}{*}{ Station } & \multicolumn{3}{|c|}{1} & \multicolumn{3}{|c|}{5} & \multicolumn{3}{|c|}{10} & \multicolumn{3}{|c|}{15} & \multicolumn{3}{|c|}{20} \\
\hline & $N$ & $\mathrm{EC}$ & DS & $N$ & $\mathrm{EC}$ & DS & $N$ & $\mathrm{EC}$ & DS & $N$ & $\mathrm{EC}$ & DS & $N$ & $\mathrm{EC}$ & DS \\
\hline Dürnrohr & 1184 & 0.87 & 1.12 & 1259 & 0.97 & 1.07 & 956 & 1.14 & 1.08 & 503 & 1.09 & 0.94 & 70 & 1.06 & 0.82 \\
\hline Hermannskogel & 1803 & 1.36 & 1.47 & 1900 & 1.46 & 1.50 & 1292 & 1.50 & 1.43 & 646 & 0.85 & 0.80 & 81 & 0.53 & 0.53 \\
\hline Illmitz & 3573 & 0.91 & 1.23 & 1863 & 0.66 & 0.82 & & & & & & & & & \\
\hline Steinspornbrücke & 1963 & 1.35 & 1.62 & 2009 & 1.42 & 1.60 & 1196 & 1.45 & 1.50 & 173 & 1.05 & 0.93 & & & \\
\hline Stixneusiedl & 2670 & 1.05 & 1.21 & 1589 & 1.01 & 1.04 & & & & & & & & & \\
\hline TGM & 362 & 0.80 & 0.96 & 360 & 0.87 & 0.95 & 204 & 0.91 & 0.83 & 25 & 0.83 & 1.04 & & & \\
\hline
\end{tabular}


TABLE 4. Average errors of ECMWF wind directions (EC) and downscaled wind directions (DS) with respect to directions measured by sodar at the first, fifth, tenth, fifteenth, and twentieth level, respectively, for the whole dataset. Term $P$ is the probability that mean wind direction errors for ECMWF and downscaled winds are not different. In case of differences that are significant on the $95 \%$ confidence level, the smaller error is marked with an asterisk.

\begin{tabular}{|c|c|c|c|c|c|c|c|c|c|c|c|c|c|c|c|}
\hline \multirow[b]{2}{*}{ Station } & \multicolumn{3}{|c|}{1} & \multicolumn{3}{|c|}{5} & \multicolumn{3}{|c|}{10} & \multicolumn{3}{|c|}{15} & \multicolumn{3}{|c|}{20} \\
\hline & $\mathrm{EC}$ & DS & $P$ & $\mathrm{EC}$ & DS & $P$ & EC & DS & $P$ & $\mathrm{EC}$ & DS & $P$ & $\mathrm{EC}$ & DS & $P$ \\
\hline Dürnrohr & 49.8 & $39.2 *$ & 0.000 & 47.5 & $41.0 *$ & 0.000 & 42.7 & $30.2 *$ & 0.000 & 44.6 & 44.2 & 0.726 & 50.8 & 52.0 & 0.562 \\
\hline Hermannskogel & 32.0 & 30.7 & 0.570 & 29.5 & 29.2 & 0.054 & $31.3^{*}$ & 33.0 & 0.000 & 45.0 & 45.9 & 0.096 & 44.1 & 44.2 & 0.551 \\
\hline Illmitz & 42.2 & $20.1^{*}$ & 0.000 & 50.0 & $45.3 *$ & 0.001 & & & & & & & & & \\
\hline Steinspornbrücke & 34.6 & $26.0^{*}$ & 0.000 & 34.1 & $25.3 *$ & 0.000 & 33.3 & $28.5^{*}$ & 0.000 & 39.6 & 38.9 & 0.829 & & & \\
\hline Stixneusiedl & 40.6 & $33.7 *$ & 0.000 & 34.0 & $29.5 *$ & 0.000 & & & & & & & & & \\
\hline TGM & 40.3 & 40.8 & 0.076 & 40.5 & 41.4 & 0.222 & 39.9 & 43.8 & 0.646 & 52.9 & 55.9 & 0.729 & & & \\
\hline
\end{tabular}

culation of meteorology) diagnostic wind field model (Scire et al. 1990), is in operational use at the Central Institute of Meteorology and Geodynamics in Vienna (Pechinger et al. 1994). Input data to TAMOS are surface and radiosonde measurements. TAMOS uses a twostep procedure to diagnose the wind field. In the first step, a "first-guess" wind field is modified by parameterization of topographic effects, slope winds, and blocking. In the second step, measured wind data are interpolated to the grid and a weighted average of the first guess and the interpolated wind field is computed. A mass-consistent wind field is then constructed by reducing the divergence of the field to less than $10^{-5} \mathrm{~s}^{-1}$ (Goodin et al. 1980). TAMOS uses an undamped terrain-following coordinate system. We used 10 levels up to $1500 \mathrm{~m}$ AGL and a horizontal grid distance of $2 \mathrm{~km}$.

Trajectories were computed with the FLEXTRA (flexible trajectory computations) model (Stohl et al. 1995). With FLEXTRA it is possible to compute several types of kinematic trajectories (three-dimensional, constantlevel, isentropic, isobaric, and layer-averaged trajectories) using the iterative scheme after Petterssen (1940). This model was recently used by Baumann and Stohl (1997) to compare long-range trajectories with gas balloon tracks. Because balloons are actively changing height, neither three-dimensional nor constant-level trajectories can represent their paths correctly. Therefore, we developed a special version of the FLEXTRA model that adjusts the height above sea level of the computed trajectory to the height of the balloon. The height of the calculated trajectory is thus identical to the height of the balloon at every computation time step. When the balloon travels below the lowest model level, the wind at the lowest model level is used for the trajectory calculation.

CLBs are helium-filled tetrahedron-shaped balloons (also known as tetroons) made of polyester film with low elasticity that gives them nearly constant volume and density (see, e.g., Angell and Pack 1960; Angell et al. 1972; Neininger 1988). CLBs rise to a predefined equilibrium level, where their density equals that of the surrounding air. In the presence of vertical air motions (updrafts and downdrafts in a convective PBL), they follow primarily this motion like soap bubbles. In the convective PBL, the CLBs therefore make excursions of several hundred meters around their equilibrium levels. Comparisons between computed trajectories and trajectories derived from CLB flights have been done by Reisinger and Mueller (1983) for PBL trajectories and by Knudsen and Carver (1994) for stratospheric trajectories.

From 21 July to 14 August 1995, a measurement campaign was conducted in eastern Austria to investigate the dynamics of photochemical smog episodes. During this campaign, 33 CLBs were released from two sites (Vienna, $48.23^{\circ} \mathrm{N}, 16.37^{\circ} \mathrm{E}$, hereafter referred to as VIE; and Wiener Neustadt, $47.84^{\circ} \mathrm{N}, 16.25^{\circ} \mathrm{E}$, hereafter referred to as WNS) in eastern Austria (see Fig. 1) of which 27 yielded usable data (MetAir 1996). The measurements were carried out on 11 days with forecasted photochemical smog episodes. Thus, most of the CLB flights took place under convective conditions, but some flights started early in the morning before the development of a well-mixed layer.

The CLBs were equipped with radiosondes measuring pressure, temperature, and humidity, and an Omega ra-

TABLE 5. Same as Table 4 but for wind speeds.

\begin{tabular}{|c|c|c|c|c|c|c|c|c|c|c|c|c|c|c|c|}
\hline \multirow[b]{2}{*}{ Station } & \multicolumn{3}{|c|}{1} & \multicolumn{3}{|c|}{5} & \multicolumn{3}{|c|}{10} & \multicolumn{3}{|c|}{15} & \multicolumn{3}{|c|}{20} \\
\hline & $\mathrm{EC}$ & DS & $P$ & $\mathrm{EC}$ & DS & $P$ & $\mathrm{EC}$ & DS & $P$ & $\mathrm{EC}$ & DS & $P$ & $\mathrm{EC}$ & DS & $P$ \\
\hline Dürnrohr & 1.94 & $1.59 *$ & 0.000 & 2.35 & $2.13 *$ & 0.000 & 2.30 & $2.21 *$ & 0.012 & 2.46 & 2.46 & 0.528 & 2.70 & 2.71 & 0.841 \\
\hline Hermannskogel & 2.70 & $2.37 *$ & 0.000 & 2.21 & $1.93^{*}$ & 0.000 & 2.00 & $1.78^{*}$ & 0.000 & 2.73 & 2.62 & 0.317 & 2.59 & 2.66 & 0.579 \\
\hline Illmitz & 1.69 & $1.22 *$ & 0.000 & 4.76 & $3.79 *$ & 0.027 & & & & & & & & & \\
\hline Steinspornbrücke & 1.69 & $1.35^{*}$ & 0.000 & 1.71 & $1.45^{*}$ & 0.000 & 2.00 & $1.86^{*}$ & 0.001 & 3.07 & 2.98 & 0.540 & & & \\
\hline Stixneusiedl & $1.65^{*}$ & 1.71 & 0.000 & 3.25 & 3.27 & 0.072 & & & & & & & & & \\
\hline TGM & 1.73 & $1.43^{*}$ & 0.000 & 1.84 & $1.60^{*}$ & 0.002 & 2.09 & 1.95 & 0.304 & 3.61 & 3.51 & 0.995 & & & \\
\hline
\end{tabular}


TABle 6. Same as Table 3 but for daytime data only.

\begin{tabular}{|c|c|c|c|c|c|c|c|c|c|c|c|c|c|c|c|}
\hline \multirow[b]{2}{*}{ Station } & \multicolumn{3}{|c|}{1} & \multicolumn{3}{|c|}{5} & \multicolumn{3}{|c|}{10} & \multicolumn{3}{|c|}{15} & \multicolumn{3}{|c|}{20} \\
\hline & $N$ & $\mathrm{EC}$ & DS & $N$ & $\mathrm{EC}$ & DS & $N$ & $\mathrm{EC}$ & DS & $N$ & $\mathrm{EC}$ & DS & $N$ & $\mathrm{EC}$ & DS \\
\hline Dürnrohr & 577 & 0.97 & 1.30 & 586 & 0.99 & 1.24 & 438 & 1.07 & 1.13 & 218 & 0.89 & 0.80 & 30 & 0.95 & 0.72 \\
\hline Hermannskogel & 830 & 1.38 & 1.58 & 877 & 1.47 & 1.59 & 635 & 1.48 & 1.49 & 372 & 0.82 & 0.79 & 45 & 0.50 & 0.46 \\
\hline Illmitz & 1698 & 1.00 & 1.38 & 687 & 0.50 & 0.71 & & & & & & & & & \\
\hline Steinspornbrücke & 910 & 1.40 & 1.71 & 919 & 1.45 & 1.70 & 515 & 1.47 & 1.63 & 66 & 0.87 & 0.89 & & & \\
\hline Stixneusiedl & 1278 & 1.16 & 1.46 & 875 & 1.07 & 1.19 & & & & & & & & & \\
\hline TGM & 164 & 0.80 & 1.00 & 162 & 0.85 & 0.98 & 94 & 0.89 & 0.85 & & & & & & \\
\hline
\end{tabular}

dionavigation system (MetAir 1996). Typically, the CLBs were tracked for 1-3 h (average $91 \mathrm{~min}$ ). Unfortunately, due to a technical failure, no balloon positions could be determined with the radionavigation system. As a backup, fortunately, the CLBs were tracked with an optical theodolite. Using these data and the pressure measurements from the radiosondes, balloon positions could be determined for the first parts of the flights. The accuracy of these positions was approximately $500 \mathrm{~m}$ at $10-\mathrm{km}$ distance from the release point (on tracking errors with optical theodolites see Connell and Miller 1995). At very low elevation angles, the vertical movements of the balloons (known from the pressure readings) were also used to estimate the distances by comparing them with differential changes in the elevation angle. This method, and the inclusion of refractivity effects, led to an extension of reliable theodolite tracking up to about $20-\mathrm{km}$ downrange. The CLBs were optically tracked for up to more than $1 \mathrm{~h}$. The average length of the trajectories determined this way was $8.1 \mathrm{~km}$. Typically, the CLBs rose up to their equilibrium level during the first $15 \mathrm{~min}$ of the flights.

First, the lengths of the trajectories up to the times when the CLBs were lost by the person tracking them were computed (Table 9). Averaged over all 27 cases, the CLB trajectories traveled a longer distance $(8.1 \mathrm{~km})$ than any of the calculated trajectories. Of the calculated trajectories, the downscaled ones were the longest (7.2 $\mathrm{km})$ and the ECMWF ones were the shortest $(6.8 \mathrm{~km})$.

Next, the separation of the calculated trajectory endpoints from the CLB trajectory endpoints was investigated (Table 9). The mean separation of both ECMWF and TAMOS trajectories from the CLB trajectories was $4.4 \mathrm{~km}$ or $54 \%$ of the average distance traveled by the CLBs. For the downscaled trajectories, the respective values were $3.3 \mathrm{~km}$ and $41 \%$. The agreement between calculated and CLB trajectories was better for trajectories starting from VIE than for those starting from WNS for all trajectory types, which is most likely due to the more complex topography near WNS. At both locations, however, the downscaled trajectory endpoints were closest to the CLB trajectory endpoints.

Finally, an intercomparison of the performance of the different models was done. In 19 cases downscaled trajectories were closer to CLB trajectories than ECMWF trajectories, in 3 cases both models produced almost identical trajectories, and in 5 cases ECMWF trajectories were better than downscaled ones. Compared to TAMOS trajectories, downscaled trajectories were better in 21 cases, while the former ones were better in 6 cases. In 13 cases ECMWF trajectories were better than TAMOS trajectories, while in 14 cases the opposite was found. We investigated whether the poor performance of the TAMOS model was caused by the divergence minimization algorithm but found that results without divergence minimization came out very similar.

Figure 4 presents four interesting examples of trajectory intercomparisons. Figure 4a shows a trajectory starting from VIE. In this case, the CLB trajectory agreed very well with both downscaled and ECMWF trajectories. Near the ground, the CLB drifted with a slow southeast wind. After gaining altitude, it entered a stronger southerly flow. The downscaled wind fields above the second model level were highly homogeneous, explaining the low uncertainties of the computed trajectories. The TAMOS trajectory agreed somewhat less favorably. Its curvature did not agree with that of the CLB trajectory, an indication that the vertical wind shear was not modeled correctly.

Figure $4 \mathrm{~b}$ is interesting because the computed downscaled trajectory agreed reasonably with the CLB trajectory, although the altitude of the CLB fluctuated

TABLE 7. Same as Table 4 but for daytime data only.

\begin{tabular}{|c|c|c|c|c|c|c|c|c|c|c|c|c|c|c|c|}
\hline \multirow[b]{2}{*}{ Station } & \multicolumn{3}{|c|}{1} & \multicolumn{3}{|c|}{5} & \multicolumn{3}{|c|}{10} & \multicolumn{3}{|c|}{15} & \multicolumn{3}{|c|}{20} \\
\hline & $\mathrm{EC}$ & DS & $P$ & $\mathrm{EC}$ & DS & $P$ & $\mathrm{EC}$ & DS & $P$ & $\mathrm{EC}$ & DS & $P$ & $\mathrm{EC}$ & DS & $P$ \\
\hline Dürnrohr & 49.1 & $35.0 *$ & 0.000 & 49.3 & $36.5^{*}$ & 0.000 & 47.4 & $38.1^{*}$ & 0.000 & 51.8 & $47.6^{*}$ & 0.022 & 61.6 & 67.5 & 0.731 \\
\hline Hermannskogel & 34.0 & $29.0 *$ & 0.000 & 32.2 & $27.8^{*}$ & 0.000 & 34.1 & 31.9 & 0.147 & 48.2 & $45.6^{*}$ & 0.039 & 47.5 & 47.0 & 0.467 \\
\hline Illmitz & 42.0 & $30.2 *$ & 0.000 & 53.0 & $48.0 *$ & 0.000 & & & & & & & & & \\
\hline Steinspornbrücke & 35.6 & $23.7 *$ & 0.000 & 34.3 & $22.2 *$ & 0.000 & 32.6 & $23.9^{*}$ & 0.000 & 40.8 & 35.8 & 0.272 & & & \\
\hline Stixneusiedl & 34.9 & $26.9 *$ & 0.000 & 34.1 & $27.2 *$ & 0.000 & & & & & & & & & \\
\hline TGM & $35.0 *$ & 37.0 & 0.032 & $34.5^{*}$ & 37.1 & 0.026 & 38.2 & 46.5 & 0.580 & & & & & & \\
\hline
\end{tabular}


Table 8. Same as Table 5 but for daytime data only.

\begin{tabular}{|c|c|c|c|c|c|c|c|c|c|c|c|c|c|c|c|}
\hline \multirow[b]{2}{*}{ Station } & \multicolumn{3}{|c|}{1} & \multicolumn{3}{|c|}{5} & \multicolumn{3}{|c|}{10} & \multicolumn{3}{|c|}{15} & \multicolumn{3}{|c|}{20} \\
\hline & $\mathrm{EC}$ & DS & $P$ & $\mathrm{EC}$ & DS & $P$ & $\mathrm{EC}$ & DS & $P$ & $\mathrm{EC}$ & DS & $P$ & $\mathrm{EC}$ & DS & $P$ \\
\hline Dürnrohr & 2.05 & $1.52 *$ & 0.000 & 2.13 & $1.85^{*}$ & 0.000 & 2.16 & 2.15 & 0.081 & 2.31 & 2.36 & 0.643 & 1.99 & 2.04 & 0.867 \\
\hline Hermannskogel & 2.46 & $1.94 *$ & 0.000 & 2.12 & $1.63^{*}$ & 0.000 & 2.03 & $1.65^{*}$ & 0.000 & 2.83 & 2.65 & 0.165 & 2.57 & 2.66 & 0.660 \\
\hline Illmitz & 1.63 & $1.10^{*}$ & 0.000 & 3.23 & $2.99 *$ & 0.005 & & & & & & & & & \\
\hline Steinspornbrücke & 1.69 & $1.18^{*}$ & 0.000 & 1.58 & $1.17 *$ & 0.000 & 1.74 & $1.49 *$ & 0.000 & 2.87 & 2.69 & 0.499 & & & \\
\hline Stixneusiedl & 1.67 & 1.66 & 0.815 & 2.11 & 2.01 & 0.087 & & & & & & & & & \\
\hline TGM & 1.83 & $1.34 *$ & 0.000 & 1.82 & $1.38 *$ & 0.000 & 1.63 & 1.43 & 0.108 & & & & & & \\
\hline
\end{tabular}

strongly and its travel direction changed twice because of a strong vertical wind shear. Near the ground, the balloon followed a southeast wind before it ascended and turned northward. Then it sank and again entered the layer with southeast wind. It is remarkable that the downscaled trajectory reproduced the sharp turns of the CLB, although the modeled wind speeds were somewhat too high. The ECMWF trajectory performed worse because the sharp turns and the general travel direction were not modeled correctly. The TAMOS trajectory was even worse. Although its general travel direction was simulated correctly, it failed in reproducing the turns caused by the vertical wind shear.

Figure $4 c$ presents an example where all computed trajectories failed entirely to reproduce the CLB trajectory. The downscaled and especially the ECMWF trajectories travelled far too slowly and even their directions did not correspond with that of the CLB. The travel speed of the TAMOS trajectory agreed with that of the CLB, but it headed in a completely wrong direction.

Figure $4 \mathrm{~d}$ shows the case with the best agreement between TAMOS and CLB trajectory. The ECMWF trajectory traveled too slow, while for the downscaled trajectory the travel direction was incorrect. For a long time, the CLB flew close to the ground, below the topography of the ECMWF model, causing both ECMWF and downscaled trajectories to be advected with the winds at the lowest model level, which explains their low speed.

TABLE 9. Summary statistics of the comparisons between computed and CLB trajectories. Term $N$ is the number of cases, length denotes the average radial distance of the trajectory endpoints from the starting points in kilometers, distance gives the average distance between the calculated trajectory endpoints and the CLB trajectory endpoints, and DS refers to downscaled trajectories.

\begin{tabular}{clcccc}
\hline \hline & & CLB & ECMWF & DS & TAMOS \\
\hline All cases & Length $(\mathrm{km})$ & 8.1 & 6.8 & 7.2 & 7.1 \\
$N=27$ & Distance $(\mathrm{km})$ & 0.0 & 4.4 & 3.3 & 4.4 \\
VIE & Length $(\mathrm{km})$ & 8.8 & 6.7 & 6.9 & 6.7 \\
$N=13$ & Distance $(\mathrm{km})$ & 0.0 & 3.9 & 2.8 & 3.8 \\
WNS & Length $(\mathrm{km})$ & 7.4 & 6.8 & 7.5 & 7.4 \\
$N=14$ & Distance $(\mathrm{km})$ & 0.0 & 4.8 & 3.8 & 5.0 \\
\hline
\end{tabular}

\section{Summary and conclusions}

We described a method based on routine meteorological data to produce high-resolution wind analyses throughout the PBL. The method extrapolates information from high-frequency surface wind measurements to greater heights by assuming that the vertical shear of the horizontal wind, that is, the differential vertical wind profile, is spatially more homogeneous than the wind profile itself. Under this assumption, it is sufficient to take only the surface winds from highresolution measurements, whereas vertical profiles of differential winds - for which high-resolution measurements do not exist on a routine basis - can be taken from low-resolution initialized analyses of numerical weather prediction models or from objective wind analyses based on radiosondes. Our algorithm results in high-resolution wind fields throughout the PBL. The method can thus be viewed as a diagnostic downscaling of large-scale wind fields.

A comparison of ECMWF analyzed winds and radiosonde wind measurements showed that these data are of similar quality. Because of the higher spatial and temporal resolution of ECMWF analyses, we used these data to calculate the differential vertical wind profiles rather than radiosonde data.

The downscaling method was developed for application in flat terrain under convective conditions when the assumption of spatially homogeneous differential vertical wind profiles is best fulfilled and surface measurements have a high representativity. Using sodar measurements, we validated that it actually improved the wind analyses of the ECMWF under these conditions, especially in the lowest $500 \mathrm{~m}$ of the PBL. As expected, improvements were greater during the day than during the night, but smaller improvements were also found during the night. Comparisons with trajectories derived from CLB flights showed that trajectories computed from downscaled wind fields were more accurate than trajectories computed from original ECMWF wind fields. They were also more accurate than trajectories computed from wind fields of a conventional diagnostic wind field model.

The basic assumption of horizontally homogeneous differential vertical wind profiles is not generally fulfilled in mountainous areas under stable conditions. 
1995072264348
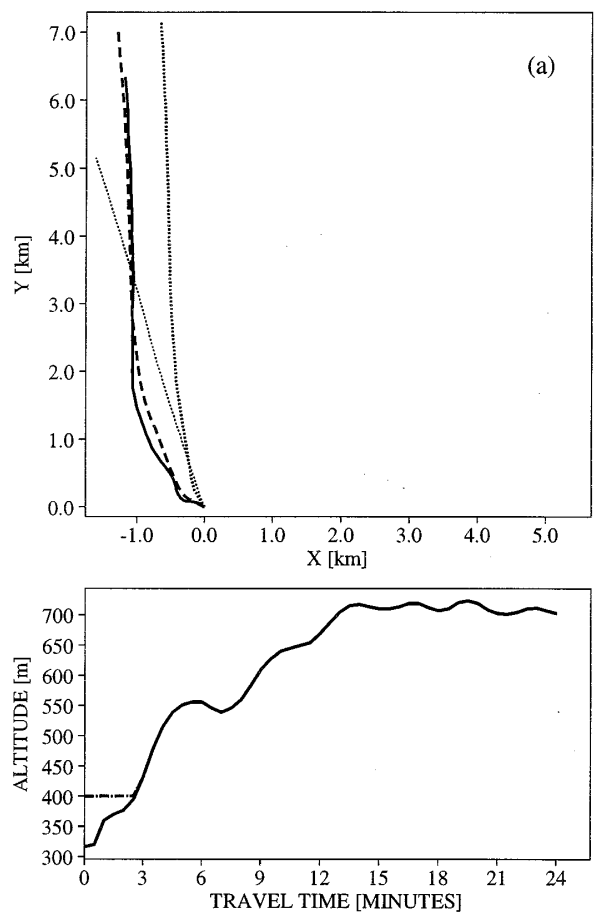

19950814101155
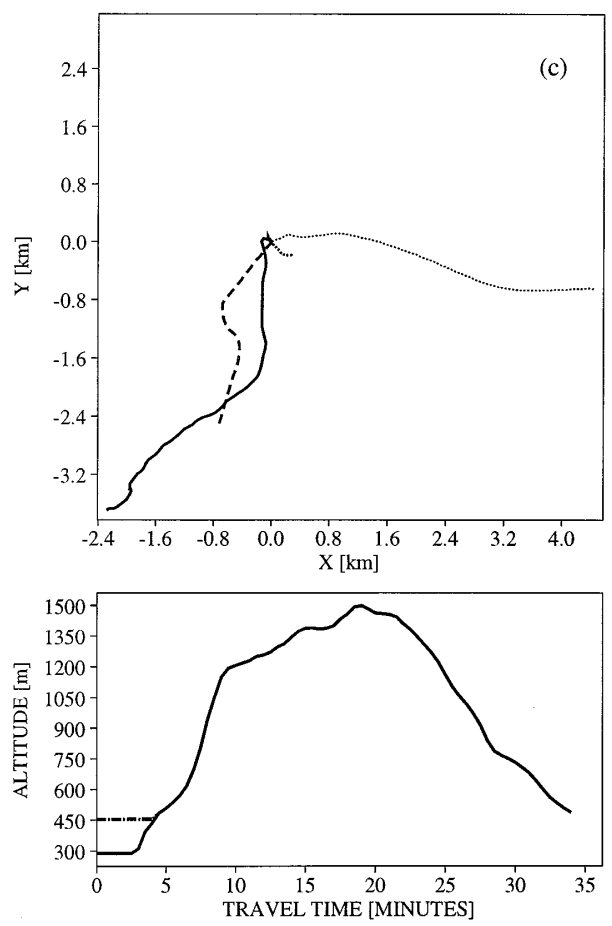

19950813115015
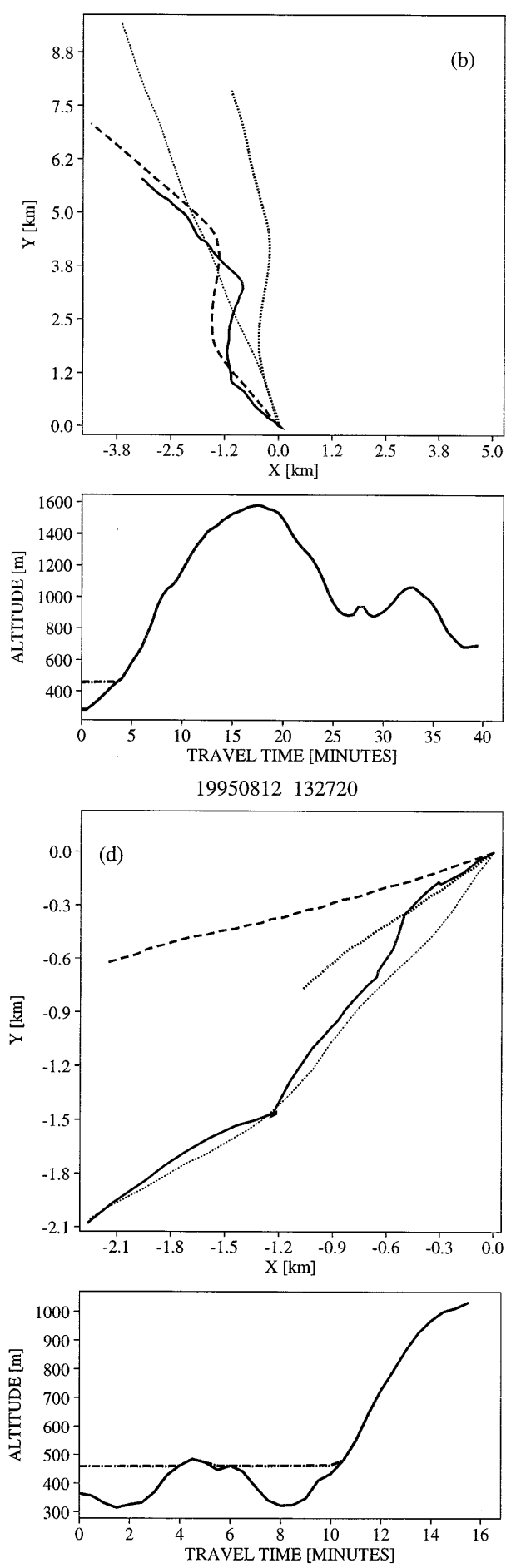

FIG. 4. Four interesting examples of trajectory intercomparisons. The uppermost lines in (a)-(d) give the starting dates and times of the CLB. The CLB starting point in (a) was VIE, in (b)-(d) it was WNS. The upper figures show the tracks of the trajectories in kilometers relative to the starting location, the lower figures show their height versus travel time. Thick solid line is the CLB trajectory, thick dashed line is the downscaled trajectory, thick dotted line is the ECMWF trajectory, and thin dotted line is the TAMOS trajectory. 
Nevertheless, Baumann et al. (1996) recently tried the downscaling method under these conditions, comparing trajectories with hot-air balloon flights in an alpine valley in wintertime. Although agreement of the computed trajectories with the balloon tracks was much worse than in the cases presented here, the downscaling still improved ECMWF wind fields considerably, while the TAMOS model failed to describe the airflow in the valley.

The performance of the downscaling method was better than the performance of the TAMOS diagnostic wind field model, both in the cases presented here and in complex terrain (Baumann et al. 1996). We believe that this is due to insufficient temporal and spatial resolution of sounding data being available to the diagnostic model. The lack of vertical wind information is a principal problem of diagnostic wind field models and not a specific shortcoming of the TAMOS model. It was already noted by Strimaitis et al. (1991), who compared trajectories computed from a diagnostic model with tracerderived trajectories, that calculated trajectories often deviate strongly from tracer-derived trajectories because of a lack of input data.

Interpolating radiosonde data directly to a grid reduces the effective resolution of a diagnostic model at higher levels to the coarse resolution of the radiosonde network. This resolution is coarser than that of current numerical weather prediction models. Therefore, there is little advantage in using conventional diagnostic wind field models when analyses of numerical weather prediction models are available. In addition, these latter analyses are usually of a higher quality than those of diagnostic models because up-to-date data assimilation techniques such as three-dimensional variational assimilation are used and the meteorological fields are dynamically balanced. These analyses fulfill physical constraints and are not a pure result of mathematical interpolation. Thus, it is preferable to use methods for downscaling analyses of a numerical weather prediction model instead of using conventional diagnostic wind field models when highly resolved wind analyses are needed. For real-time applications, the method can also be used to improve upper-level wind analyses based on radiosonde data only (Baumann et al. 1996).

The downscaling method as presented in this paper is essentially a new method to interpolate wind measurements to a fine grid, the difference to conventional interpolation being that interpolating differential winds gives more accurate results than interpolating winds directly. It may thus be combined with other features of diagnostic wind field models to improve its performance. Interpolation errors can be reduced by introducing a statistical interpolation method. It would be rewarding to transform the data to a coordinate system that follows the finescale topography and to adjust the winds to fulfill mass conservation. Parameterizations of topographical effects could also be used.

Acknowledgments. This study was financed by the
"Jubiläumsfonds der Oesterreichischen Nationalbank" as part of the project "KONGEX." The CLB measurements were financed jointly by the Austrian ministries of Science, of the Environment and of Agriculture, and the Austrian federal states of Burgenland, Lower Austria, and Vienna as part of the "POP" project. Thanks are also due to W. Spangl from the Austrian Environmental Protection Agency for their sodar measurements and to R. Steinacker for allowing us to use his theodolites. Valuable discussions with H. Kromp-Kolb and P. Seibert are gratefully acknowledged. The comments and suggestions of two anonymous reviewers were very helpful for revising the paper.

\section{REFERENCES}

Angell, J. K., and D. H. Pack, 1960: Analysis of some preliminary low-level constant level balloon (tetroon) flights. Mon. Wea. Rev., 88, 235-248.

, - L. Machta, C. R. Dickson, and W. H. Hoecker, 1972: Three-dimensional air trajectories determined from tetroon flights in the planetary boundary layer of the Los Angeles basin. J. Appl. Meteor., 11, 451-471.

Baumann, K. M., and A. Stohl, 1997: Validation of a long-range trajectory model using gas balloon tracks from the Gordon Bennett Cup 95. J. Appl. Meteor., 36, 711-720.

—, M. Langer, and A. Stohl, 1996: Hot-air balloon tracks used to analyze air flow in alpine valleys. Proc. 24th Conf. on Alpine Meteorology, Bled, Slovenia, Hydrometeorological Institute of Slovenia, 60-66.

Beljaars, A. C. M., and A. K. Betts, 1992: Validation of the boundary layer representation in the ECMWF model. Seminar Proc. Validation of Models Over Europe, Vol II, Reading, U.K., ECMWF, 159-195.

Breaker, L. C., W. H. Gemmill, and D. S. Crosby, 1994: The application of a technique for vector correlation to problems in meteorology and oceanography. J. Appl. Meteor., 33, 1354-1365.

Bridger, A. F. C., A. J. Becker, F. I. Ludwig, and R. M. Endlich, 1994: Evaluation of the WOCSS wind analysis scheme for the San Francisco Bay area. J. Appl. Meteor., 33, 1210-1218.

Brocchini, M., M. Wurtele, G. Umgiesser, and S. Zecchetto, 1995: Calculation of a mass-consistent two-dimensional wind field with divergence control. J. Appl. Meteor., 34, 2543-2555.

Connell, B. H., and D. R. Miller, 1995: An interpretation of radiosonde errors in the atmospheric boundary layer. J. Appl. Meteor., 34, 1070-1081.

Crosby, D. S., L. C. Breaker, and W. H. Gemmill, 1993: A proposed definition for vector correlation in geophysics: Theory and application. J. Atmos. Oceanic Technol., 10, 355-367.

Daley, R., 1991: Atmospheric Data Analysis. Cambridge University Press.

ECMWF, 1989: Research Manual 2. ECMWF Forecast Model-Adiabatic Part. $2 \mathrm{~d}$ ed. European Centre for Medium-Range Weather Forecasts.

Goodin, W. R., G. McRae, and J. H. Seinfeld, 1979: A comparison of interpolation methods for sparse data: Application to wind and concentration fields. J. Appl. Meteor., 18, 761-771.

,-- , and -1980 : An objective analysis technique for constructing three-dimensional urban-scale wind fields. J. Appl. Meteor., 19, 98-108.

Graber, W. K., and W. Portmann, 1993: Modeling wind fields over complex terrain by super-position of scale-related processes and its application to the Alpine air mass exchange. Meteor. Z., N.F. 2, 153-166.

Hanna, S. R., and J. C. Chang, 1992: Representativeness of wind measurements on a mesoscale grid with station separations of $312 \mathrm{~m}$ to $10 \mathrm{~km}$. Bound.-Layer Meteor., 60, 309-324. 
Jakobs, H. J., H. Feldmann, H. Hass, and M. Memmesheimer, 1995: The use of nested models for air pollution studies: An application of the EURAD model to a SANA episode. J. Appl. Meteor., 34, 1301-1319.

Kahl, J. D., and P. J. Samson, 1986: Uncertainty in trajectory calculations due to low resolution meteorological data. J. Climate Appl. Meteor., 25, 1816-1831.

$\longrightarrow$, and - 1988a: Trajectory sensitivity to rawinsonde data resolution. Atmos. Environ., 22, 1291-1299.

$\longrightarrow$, and - 1988b: Uncertainty in estimating boundary-layer transport during highly convective conditions. J. Appl. Meteor., 27, 1024-1035.

Knudsen, B. M., and G. D. Carver, 1994: Accuracy of the isentropic trajectories calculated for the EASOE campaign. Geophys. Res. Lett., 21, 1199-1202.

Koracin, D., and R. Berkowicz, 1988: Nocturnal boundary-layer height: Observations by acoustic sounders and predictions in terms of surface-layer parameters. Bound.-Layer Meteor., 43, $65-83$.

Kunz, R., and N. Moussiopoulos, 1995: Simulation of the wind field in Athens using refined boundary conditions. Atmos. Environ., 29, 3375-3391.

Ludwig, F. L., J. M. Livingston, and R. M. Endlich, 1991: Use of mass conservation and critical dividing streamline concepts for efficient objective analzsis of wind fields in complex terrain. $J$. Appl. Meteor., 30, 1490-1499.

Mathur, R., and L. K. Peters, 1990: Adjustment of wind fields for application in air pollution modeling. Atmos. Environ., 24A, 1095-1106.

McQueen, J. T., R. R. Draxler, and G. D. Rolph, 1995: Influence of grid size and terrain resolution on wind field predictions from an operational mesoscale model. J. Appl. Meteor., 34, 21662181.

MetAir, 1996: Schlussbericht Schwebeballonflüge und Berechnungen zu Mischungsschichten für das Pannonische Ozonprojekt (POP)-Kampagne 1995. Rep. to the Austrian Environmental Protection Agency, 197 pp. [Available from Umweltbundesamt, Spittelaner Lande 5, 1090 Vienna, Austria.]

Moussiopoulos, N., and T. Flassak, 1986: Two vectorized algorithms for the effective calculation of mass-consistent flow fields. $J$. Climate Appl. Meteor., 25, 847-857.

Neininger, B., 1988: Quasi-Langrange'sche Turbulenzmessung mit Schwebeballonen in der Planetaren Grenzschicht. Lenticularis AG, Opfikon, Switzerland.

Palomino, I., and F. Martin, 1995: A simple method for spatial interpolation of the wind in complex terrain. J. Appl. Meteor., 34, 1678-1693.

Pechinger, U., K. v.d. Emde, M. Langer, and C. Streissler, 1994: Immissionsabschätzung bei Nuklearunfällen. Rep. of the Central Institute of Meteorology and Geodynamics to the Austrian Ministry of Health and Sports, 149 pp. [Available from Central Institute of Meteorology and Geodynamics, Hohe Warte 38, A1190 Vienna, Austria.]

Peters, L. K., and Coauthors, 1995: The current state and future direction of Eulerian models in simulating the tropospheric chemistry and transport of trace species: A review. Atmos. Environ., 29, 189-222.
Petterssen, S., 1940: Weather Analysis and Forecasting. McGrawHill.

Piringer, M., 1994: Selected results of a sodar intercomparison experiment. Meteor. Z., N.F. 3, 132-137.

_ 1996: Data availability of commercial sodars depending on meteorological conditions. Preprints, Eighth Symp. on Acoustic Remote Sensing, Russian Academy of Science, Moscow, Russia, 27-31.

— M. Jaritz, E. Petz, M. Langer, and B. Pospisil, 1995: Vertikalprofilstudie Wien-Untersuchung sommerlicher Ozonepisoden in Wien anhand der Vertikalstruktur der planetaren Grenzschicht. Rep. to MA22, 225 pp. [Available from Central Institute of Meteorology and Geodynamics, Hohe Warte 38, A1190 Vienna, Austria.]

Press, W. H., S. A. Teukolsky, W. T. Vetterling, and B. P. Flannery, 1992: Numerical Recipes in FORTRAN. The Art of Scientific Computing. 2d ed. Cambridge University, 963 pp.

Reisinger, L. M., and S. F. Mueller, 1983: Comparisons of tetroon and computed trajectories. J. Climate Appl. Meteor., 22, 664672.

Richner, H., and T. Griesser, 1993: Air motion from potential temperature analysis on a meso- $\beta$-scale over complex terrain during POLLUMET 1990 and 1991. Meteor. Z., N.F. 2, 145-152.

Ross, D. G., I. N. Smith, P. C. Manins, and D. G. Fox, 1988: Diagnostic wind field modeling for complex terrain: Model development and testing. J. Appl. Meteor., 27, 785-796.

Schlünzen, K. H., 1994: Mesoscale modelling in complex terrainAn overview on the German nonhydrostatic models. Beitr. Phys. Atmos., 67, 243-253.

Scire, J., E. Insley, and R. Yamartino, 1990: Model Formulation and User's Guide for the CALMET Meteorological Model. Rep. A025-1. [Available from the State of California Air Resources Board, 1131 S Street, Sacramento, CA 95812.]

Seibel, C., and K. Maßmeyer, 1995: Berechnung von Windfeldern über Nordrhein-Westfalen mit einem massenkonsistenten Windfeldmodell. Staub Reinhalt. Luft, 55, 205-210.

Sherman, C. A., 1978: A mass-consistent model for wind fields over complex terrain. J. Appl. Meteor., 17, 312-319.

Stocker, R. A., R. A. Pielke, A. J. Verdon, and J. T. Snow, 1990: Characteristics of plume releases as depicted by balloon launchings and model simulations. J. Appl. Meteor., 29, 53-62.

Stohl, A., and G. Wotawa, 1995: A method for computing single trajectories representing boundary layer transport. Atmos. Environ., 29, 3235-3239.

- - P. Seibert, and H. Kromp-Kolb, 1995: Interpolation errors in wind fields as a function of spatial and temporal resolution and their impact on different types of kinematic trajectories. $J$. Appl. Meteor., 34, 2149-2165.

Strimaitis, D. G., G. E. Moore, and S. G. Douglas, 1991: Analysis of tracer data collected during the SCCCAMP 1985 intensive measurement periods. J. Appl. Meteor., 30, 674-705.

Stull, R. B., 1988: An Introduction to Boundary Layer Meteorology. Kluwer Academic Publishers, 666 pp.

Talagrand, O., and P. Courtier, 1987: Variational assimilation of meteorological observations with the adjoint vorticity equation. I: Theory. Quart. J. Roy. Meteor. Soc., 113, 1311-1328.

Zou, X., I. M. Navon, and F. X. Ledimet, 1992: An optimal nudging data assimilation scheme using parameter estimation. Quart. J. Roy. Meteor. Soc., 118, 1163-1186. 